\title{
LOWERING SYNTHESIS TEMPERATURE OF hBN BY IMPROVEMENT OF PRECURSOR
}

\author{
Erhan Budak $^{1,2^{*}}$, Ramazan Lok ${ }^{2}$, Ercan Yilmaz ${ }^{2,3}$ \\ ${ }^{1}$ Department of Chemistry, Faculty of Art and Science, Bolu Abant Izzet Baysal University, Bolu, Turkey \\ ${ }^{2}$ Center for Nuclear Radiation Detector Research and Applications, Bolu Abant Izzet Baysal University, Bolu, Turkey \\ 3Department of Physics, Faculty of Art and Science, Bolu Abant Izzet Baysal University, Bolu, Turkey
}

\begin{abstract}
In this study, hexagonal boron nitride ( $h B N$ ) was synthesized with the modified O'Connor method in the presence of different additives. Structural properties of the synthesized materials were determined by X-Ray Diffraction, (XRD), Fourier Transform Infrared Spectroscopy, (FTIR), and Scanning Electron Microscopy (SEM). It was found that improving the precursor using different additives played a positive role by lowering the formation temperature. The average grain sizes (21-24 nm) and graphitization index (2.44-3.45) of hBN samples were calculated from the XRD pattern.
\end{abstract}

Keywords: Hexagonal boron nitride, Nanocrystalline materials, O'Connor method

\section{INTRODUCTION}

Boron nitride $(\mathrm{BN})$ is an extraordinary structure in materials science. Due to special bonding behaviors of boron and nitrogen, BN can exist in many different structures. Graphite like hexagonal boron nitride (hBN), with a wide range of applications, such as lubricants, electrical insulators, refractories, catalyst supports, and laser devices [1] has been subjected to numerous studies in the last twenty years [2]-[4]. Although there are several different methods of hBN production, high temperature $\left(\geq 1500{ }^{\circ} \mathrm{C}\right)$ solid-state synthesis reactions are most commonly used at industrial scale [5].

Due to simplicity and possibility to make changes in precursor preparation, the O'Connor method [6] was chosen to synthesize hBN in this study. In previous studies [2], [7], [8], it was claimed that the use of metal salts in the synthesis of hBN gave positive results: interlayer spacing was affected by an electronic interaction between the transition metal and hBN layers ( $d-\pi$ interaction) [9], and metal salts worked as a catalyst, increasing the surface area of boron oxide to complete reactions with ammonia [5].

In our previous studies [2], the addition of lithium oxide to the precursor yielded better result than other lithium salts added at $1100^{\circ} \mathrm{C}$. In the current study, the effect of different metal oxides, namely $\mathrm{MgO}, \mathrm{CaO}$ and $\mathrm{BaO}$ (Group II oxides), on the formation of $\mathrm{hBN}$ has been examined.

\section{EXPERIMENTAL}

BN samples were prepared using the O'Connor method [6]. The $2 \mathrm{~g}$ of $\mathrm{B}_{2} \mathrm{O}_{3}, 4 \mathrm{~g}$ of $\mathrm{CO}\left(\mathrm{NH}_{2}\right) 2$ (urea) and $1.2 \mathrm{~g}$ of Group II oxides $(\mathrm{MgO}, \mathrm{CaO}$, and $\mathrm{BaO}$ ) were ground in a mortar. Then the mixture was pre-heated to $200^{\circ} \mathrm{C}$ for $2 \mathrm{~h}$. After that, the obtained mixture (precursor) was pulverized in the mortar again. The precursor was heated to $1100^{\circ} \mathrm{C}$ at the heating rate of $5{ }^{\circ} \mathrm{C} / \mathrm{min}$ in a tube furnace under $\mathrm{NH}_{3}$ stream (flow rate $120 \mathrm{~mL} / \mathrm{min}$ ) for $2 \mathrm{~h}$. Raw product was leached in a $10 \% \mathrm{HCl}$ solution to remove all non-reacted products and dried in an oven at $100{ }^{\circ} \mathrm{C}$.

The hBN stretching vibrations were determined using a Perkin Elmer Spectrum Two FTIR-ATR spectrophotometer. XRD patterns were obtained by a Rigaku Multiflex diffractometer using $\mathrm{CuKa}$ radiation, while micrographs were taken by the Jeol JSM 6390LV Microscope. For SEM images, the powder was placed on a tape and adhered onto a brass sample holder, followed by sputtering of gold.

\section{RESULTS AND DISCUSSION}

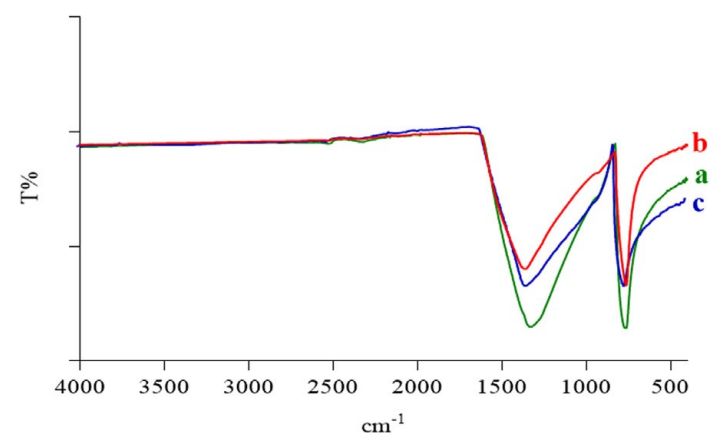

Figure 1. FTIR spectra of $\mathrm{hBN}$ samples at $1100{ }^{\circ} \mathrm{C}$ a) $\mathrm{MgO} / \mathrm{hBN}$, b) $\mathrm{CaO} / \mathrm{hBN}$, c) $\mathrm{BaO} / \mathrm{hBN}$.

Figure 1 shows two strong characteristic peaks, labeled as BN in-plane and out-of-plane vibrations, at $\sim 1340 \mathrm{~cm}^{-1}$ and $\sim 761 \mathrm{~cm}^{-1}$, respectively [7], [8], [10],

*erhan@ibu.edu.tr 
E. Budak et al., Lowering synthesis temperature of hBN..., RAP Conf. Proc., vol. 5, 2020,1-3

[11]. There is no major difference of these spectra from those typical for industrially produced hBN, although the synthesis temperature is significantly lower; also, the absorption peaks are sharp.

Crystal structure of the hBN samples was examined by XRD and the results were matched with ICDD card No: 34-421. No different phases which could have originated from Group II oxides and boron oxide were found. In diffractograms in Figure 2, all peaks, namely (002), (100), (101), (102), (004), (103), (104), (110), (112), and (oo6), were labeled as hBN.

The separation of (100) and (101) peaks, accompanied by the sharpening of (002), the appearance of (004), and increasing intensity of (102) peaks, are the most significant proofs for the crystallinity of $\mathrm{hBN}$ [1], [12]. According to these concepts, we can state that the obtained hBN powders are well crystallized. In addition, the appearance of (104) (Figure 2c) shows that the degree of crystallization was very high.

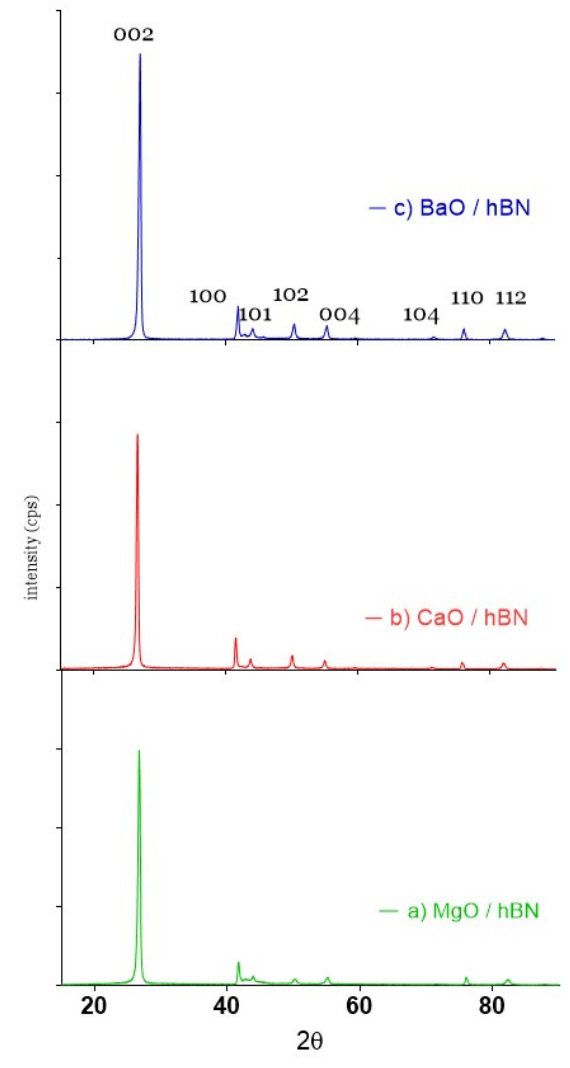

Figure. 2. XRD pattern of hBN samples at $1100{ }^{\circ} \mathrm{C}$. a) $\mathrm{MgO} / \mathrm{hBN}$, b) $\mathrm{CaO} / \mathrm{hBN}$, c) $\mathrm{BaO} / \mathrm{hBN}$.

The term "graphitization index" (G.I.) was used for estimating the degree of crystallization of the hBN and it was calculated as:

$$
\text { G. I. }=\frac{\operatorname{Area}[(100)+(101)]}{\operatorname{Area}[(102)]}
$$

G.I. value can be in the range from 1.6 to 50. A higher value of G.I. would mean less three-dimensional ordering (amorphous structure) in $\mathrm{hBN}$ and vice versa [12], [13]. In Table 1, the G.I. values of hBN are given; these low values indicate that the samples have high three-dimensional order in the crystal structure.
Table 1. Calculated lattice parameters,

grain size, and graphitization index of hBN samples.

\begin{tabular}{|c|c|c|c|c|}
\hline $\begin{array}{l}\text { Metal } \\
\text { Oxides }\end{array}$ & \multicolumn{2}{|c|}{$\begin{array}{l}\text { Lattice } \\
\text { Parameter } \\
(\AA)\end{array}$} & $\begin{array}{c}\text { Grain } \\
\text { Size } \\
(\mathrm{nm})\end{array}$ & $\begin{array}{l}\text { Graphitization } \\
\text { Index }\end{array}$ \\
\hline \multirow{3}{*}{$\mathrm{BaO}$} & ao & 2.506 & \multirow{3}{*}{24} & \multirow{3}{*}{2.44} \\
\hline & $\mathrm{c}_{\mathrm{o}}$ & 6.700 & & \\
\hline & $\mathrm{d}$ & 3.350 & & \\
\hline \multirow{3}{*}{$\mathrm{CaO}$} & $a_{0}$ & 2.496 & \multirow{3}{*}{22} & \multirow{3}{*}{2.74} \\
\hline & $\mathrm{c}_{0}$ & 6.602 & & \\
\hline & $\mathrm{d}$ & 3.301 & & \\
\hline \multirow{3}{*}{$\mathrm{MgO}$} & $a_{0}$ & 2.502 & \multirow{3}{*}{21} & \multirow{3}{*}{3.45} \\
\hline & $\mathrm{c}_{\mathrm{O}}$ & 6.664 & & \\
\hline & $\mathrm{d}$ & 3.332 & & \\
\hline
\end{tabular}
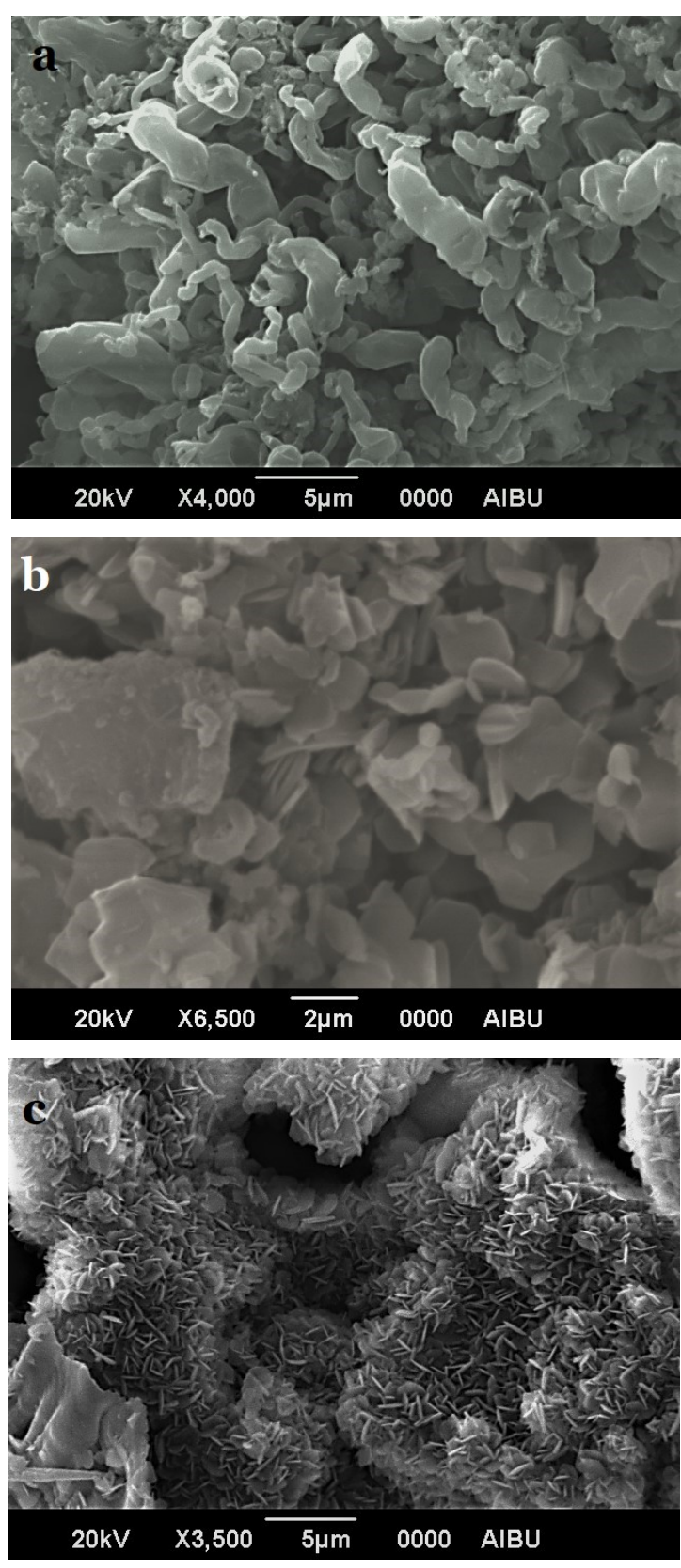

Figure 3. SEM images of hBN samples at $1100{ }^{\circ} \mathrm{C}$. a) $\mathrm{MgO} / \mathrm{hBN}$, b) $\mathrm{CaO} / \mathrm{hBN}$, c) $\mathrm{BaO} / \mathrm{hBN}$. 
The lattice constants, interlayer distance, and average grain size (Scherrer equations) were calculated for the samples after refinement and are also given in Table 1 . The results are very close to the reported values for hBN; namely the ICDD card No: $34-421$ has $\mathrm{a}_{o}=2.504 \AA, \mathrm{c}_{\mathrm{o}}=6.656 \AA$, and $\mathrm{d}=3.328 \AA$.

The use of both ammonia and metals lowered the formation temperature of hBN - metals act as catalysts [14]-[16] and ammonia acts as a nitriding agent [10], [17]. Furthermore, the usage of metal salts increases the boron oxide surface so that the full reaction of boron oxide and ammonia is possible [5]. According to these statements and results of the aforementioned FTIR and XRD analyses, Group II oxides play the role of a catalyst, lowering the formation temperature of $\mathrm{hBN}$ and increasing its crystallinity. The use of $\mathrm{BaO}$ provided best results among the three studied oxides; the reason may be its low melting point and greater atomic radius.

SEM images (Figure 3) indicate that the samples conglomerated and plate like crystals. The morphology difference of hBN possibly originates from the use of different metals, as in previously reported work [2], [18].

\section{CONCLUSION}

In summary, nano-sized hBN powders were synthesized at $1100^{\circ} \mathrm{C}$, a low temperature compared with $1500^{\circ} \mathrm{C}$ used at industrial scale production. Group II oxides lowered the synthesis temperature of hBN by increasing the boron oxide and ammonia interaction. Also, metal oxides affected the morphology of hBN and G.I.

Acknowledgements: This work was supported by Presidency of Turkey, Presidency of Strategy and Budget, under Contract Number: 2016K12-2834.

\section{REFERENCES}

1. R. T. Paine, C. K. Narula, "Synthetic routes to boron nitride," Chem. Rev., vol. 90, no. 1, pp. 73 - 91, Jan. 1990. DOI: $10.1021 /$ crooo99a004

2. E. Budak, "Low temperature synthesis of hexagonal boron nitride by solid state reaction in the presence of lithium salts," Ceram. Int., vol. 44, no. 11, pp. $13161-13164$, Aug. 2018. DOI: $10.1016 /$ j.ceramint.2018.04.139

3. B. Matovic et al., "New synthetic route for nanocrystalline boron nitride powder," Mater. Lett., vol. 65, no. 2, pp. 307 - 309, Jan. 2011. DOI: $10.1016 /$ j.matlet.2010.10.005

4. A. Sumiyoshi, H. Hyodo, K. Kimura, "Li-intercalation into hexagonal boron nitride," J. Phys. Chem. Solids, vol. 71, no. 4, pp. 569 - 571, Apr. 2010.

DOI: $10.1016 / j$.jpcs.2009.12.038
5. R. Haubner, M. Wilhelm, R. Weissenbacher, B. Lux, "Boron Nitrides - Properties, Synthesis and Applications" in High Performance Non-Oxide Ceramics II, vol. 102, M. Jansen, 1st ed., Berlin/ Heidelberg, Germany: Springer, 2002, pp. $1-45$. DOI: $10.1007 / 3-540-45623-6 \quad 1$

6. T. E. O'Connor, "Synthesis of boron nitride," J. Am. Chem. Soc., vol. 84, no. 9, pp. 1753 - 1754, May 1962. DOI: $10.1021 /$ jaoo868ao65

7. E. Budak, C.. Bozkurt, "The effect of transition metals on the structure of h-BN intercalation compounds," $J$. Solid State Chem., vol. 177, no. 4- 5, pp. 1768 - 1700, Apr. - May 2004.

DOI: $10.1016 /$ j.jssc.2003.12.038

8. E. Budak, Ç. Bozkurt, "Synthesis of hexagonal boron nitride with the presence of representative metals," Phys. B: Condens. Matter, vol. 405, no. 22, pp. $4702-4705$, Nov. 2010. DOI: 10.1016/j.physb.2010.08.067

9. M. Hubáček, T. Sato, M. Ueki, "Copper-boron nitride interaction in hot-pressed ceramics," J. Mater. Res., vol. 12, no. 1, pp. 113 - 118, Jan. 1997. DOI: 10.1557/JMR.1997.0018

10. M. Hubáček, T. Sato, T. Ishii, "A coexistence of boron nitride and boric oxide," J. Solid State Chem., vol. 109, no. 2, pp. 384 - 390, Apr. 1994

DOI: $10.1006 /$ jssc.1994.1117

11. L. Chen et al., "Low-temperature synthesis and benzene-thermal growth of nanocrystalline boron nitride," J. Cryst. Growth, vol. 273, no. 3 - 4, pp. $646-650$, Jan. 2005. DOI: 10.1016/j.jcrysgro.2004.09.062

12. J. Thomas, N. E. Weston, T. E. O'Connor, "Turbostratic boron nitride, thermal transformation to ordered-layerlattice boron nitride," J. Am. Chem. Soc., vol. 84, no. 24 , pp. $4619-4622$, Dec. 1962.

DOI: 10.1021/jaoo883a001

13. M. G. Balint, M. I. Petrescu, "An attempt to identify the presence of polytype stacking faults in $\mathrm{hBN}$ powders by means of X-ray diffraction," Diam. Relat. Mater., vol. 18, no. 9, pp. 1157 - 1162, Sep. 2009.

DOI: 10.1016/j.diamond.2009.02.035

14. M. Zheng, Y. Gu, Z. Xu, Y. Liu, "Synthesis and characterization of boron nitride nanoropes," Mater. Lett., vol. 61, no. 8 - 9, pp. 1943 - 1945, Apr. 2007. DOI: 10.1016/j.matlet.2006.07.108

15. G. W. Zhou, Z. Zhang, Z. G. Bai, D. P. Yu, "Catalyst effects on formation of boron nitride nano-tubules synthesized by laser ablation," Solid State Commun., vol. 109, no. 8, pp. 555 - 559, Feb. 1999. DOI: 10.1016/So038-1098(98)00541-9

16. L. Shi et al., "Formation of nanocrystalline BN with a simple chemical route," Mater. Lett., vol. 58, no. 26, pp. $3301-3303$, Oct. 2004. DOI: 10.1016/j.matlet.2004.06.022

17. M. Hubáček, T. Sato, "Preparation and properties of a compound in the b-c-n system," J. Solid State Chem., vol. 114, no. 1, pp. 258 - 264, Jan. 1995. DOI: $10.1006 /$ jssc.1995.1037

18. H. E. Çamurlu, A. Gençer, B. Becer, "Comparative catalytic study on the carbothermic formation of hexagonal boron nitride with $\mathrm{Li}, \mathrm{Na}, \mathrm{K}$ and $\mathrm{Ca}$ carbonates," J. Mater. Sci., vol. 49, no. 1, pp. 371 - 379, Jan. 2014.

DOI: $10.1007 / \mathrm{s} 10853-013-7714-\mathrm{x}$ 